\title{
Inhibitory effect of oxidative damage on cardiomyocyte differentiation from Wharton's jelly-derived mesenchymal stem cells
}

\author{
NATAKARN NIMSANOR ${ }^{1}$, JITRADA PHETFONG $^{2}$, CHOTIROS PLABPLUENG $^{2}$, \\ KULACHART JANGPATARAPONGSA ${ }^{2}$, VIRAPONG PRACHAYASITTIKUL ${ }^{3}$ and AUNGKURA SUPOKAWEJ ${ }^{1}$ \\ ${ }^{1}$ Department of Clinical Microscopy; ${ }^{2}$ Center for Research and Innovation; ${ }^{3}$ Department of Clinical Microbiology and \\ Applied Technology, Faculty of Medical Technology, Mahidol University, Salaya, Nakhon Pathom 73170, Thailand
}

Received March 16, 2017; Accepted July 27, 2017

DOI: $10.3892 /$ etm.2017.5249

\begin{abstract}
Ischemic heart diseases are a serious health problem worldwide. The transplantation of mesenchymal stem cells (MSCs) has been investigated in numerous clinical trials on various other diseases due to the self-renewal capacity of these cells and their potential to differentiate into a variety of cell types. The presence of excess reactive oxygen species in injured myocardium causes cardiac dysfunction and leads to inefficient repair of the heart. The poor outcomes of stem cell transplantation have been suggested to result from residual oxidative damage affecting the transplanted cells. The aim of the present study was to compare the effects of hydrogen peroxide $\left(\mathrm{H}_{2} \mathrm{O}_{2}\right)$ on Wharton's jelly-derived MSCs (WJ-MSCs) and bone marrow-derived MSCs (BM-MSCs) in vitro, in order to provide information useful for the future selection of MSC types for cardiac differentiation and transplantation. $\mathrm{H}_{2} \mathrm{O}_{2}$ at concentrations of 200,500 and $1,000 \mu \mathrm{M}$ was applied to WJ-MSCs and BM-MSCs under cardiogenic differentiation conditions. The morphology of MSCs treated with $\mathrm{H}_{2} \mathrm{O}_{2}$ was similar to that of untreated cells, whereas the cell density decreased in direct association with the dose of $\mathrm{H}_{2} \mathrm{O}_{2}$. Cardiac differentiation markers were then evaluated by immunofluorescence analysis of GATA4 and cardiac troponin $\mathrm{T}(\mathrm{cTnT})$. The fluorescence intensity levels of the two markers were identified to be diminished by increasing doses of $\mathrm{H}_{2} \mathrm{O}_{2}$ from 500 to $1,000 \mu \mathrm{M}$. The expression levels of homeobox protein $\mathrm{Nkx} 2.5$, $c \operatorname{cnT}$ and cardiac $\alpha$-actin were also examined, and were identified to be low in the WJ-MSCs treated with $1,000 \mu \mathrm{M} \mathrm{H}_{2} \mathrm{O}_{2}$, which was similar to the findings observed in BM-MSCs. These
\end{abstract}

Correspondence to: Dr Aungkura Supokawej, Department of Clinical Microscopy, Faculty of Medical Technology, Mahidol University, 999 Putthamonthon Sai 4, Putthamonthon, Salaya, Nakhon Pathom 73170, Thailand

E-mail: aungkura.jer@mahidol.ac.th

Key words: mesenchymal stem cells, Wharton's jelly, oxidative stress, hydrogen peroxide, cardiomyocytes results suggested that oxidative stress affects cardiomyocyte differentiation via the downregulation of cardiac genes and cardiac proteins. Furthermore, it should be noted that there was a marked difference in the effect depending on the source of MSCs. This evidence provided supportive information for the use of stem cells in transplantation.

\section{Introduction}

Ischemic heart disease (IHD) is a serious health problem worldwide, as reported by the World Health Organization in 2016 (1). Several risk factors are associated with IHD, which include smoking, lack of exercise, diabetes mellitus and elevated cholesterol levels. The pathogenesis of IHD starts with an inflammatory reaction that leads to scar formation, interstitial fibrosis and vascular remodeling, ultimately causing dysfunction of the heart muscles. This myocardial dysfunction is due to oxidative stress under hypoxic conditions, which is influenced by the presence of reactive oxygen species (ROS). ROS, which are recognized as toxic cellular radicals, affect the viability of cardiomyocytes through the activation of apoptotic pathways (2), induction of mitochondrial damage (3) and inhibition of cardioprotective processes (4).

The conventional medical and surgical treatments for IHD aim to promote blood circulation to the myocardium in order to restore cardiomyocyte functions. However, dead myocardial tissue cannot be rescued. Thus, treatments that effectively recover damaged tissue are important for sustaining the heart function. At present, stem cell therapy is considered to be a primary option for salvaging damaged cells. The treatment of IHD using various types of stem cells, such as hematopoietic stem cells, cardiac stem cells and mesenchymal stem cells (MSCs), has been extensively studied in numerous clinical trials (5).

MSCs are multipotent stem cells that may be isolated from various tissue types, including perinatal tissues and Wharton's jelly. Wharton's jelly-derived MSCs (WJ-MSCs) are regarded as a promising tool for cell therapy due to their expression of numerous embryonic markers, such as (sex-determining region Y) box 2, NANOG, LIN28, stage-specific embryonic antigen (SSEA) 1, SSEA3, SSEA4, Kelch-like factor 4, c-MYC, 
Criptic family 1 and REX1 (6). Elevated expression levels of embryonic markers are strongly associated with pluripotency, anti-inflammatory properties (7), deceleration of senescence (8), low immunogenicity (9) and shorter doubling-time compared with bone marrow-derived MSCs (BM-MSCs) (10).

The utility of MSCs in cell therapy is due to their secretion of several survival factors. MSC secretory factors, such as transforming growth factor $\beta$, platelet-derived growth factor and fibroblast growth factor, have been reported to promote MSC proliferation and differentiation (11). In addition, these factors may also function as growth-stimulatory factors for other cell types (12). Furthermore, proteins secreted from MSCs have been demonstrated to be involved in the migration of primitive stem cells from bone marrow to local sites of injury, the reduction of scar formation and fibrosis, the enhancement of cardiac function via formation of new blood vessels and the differentiation of stem cells into cardiomyocytes (13). However, numerous studies have demonstrated poor survival of MSCs following transplantation, which is thought to be due to their response to the noxious microenvironment; oxidative stress present in the damaged tissues may cause the death of transplanted cells through apoptotic pathways and upregulation of inflammatory mediators in local injury $(14,15)$. In an attempt to counteract this, anti-oxidant enzymes may be expressed at a high level in MSCs to antagonize the environmental oxidative damage (16). However, the underlying mechanisms and effects of oxidative environments on MSC function remain to be fully established.

In the present study, WJ-MSCs were used as an alternative cell source and their response to treatment with $\mathrm{H}_{2} \mathrm{O}_{2}$ was studied. In particular, the cell number, viability and morphology as well as the expression of cardiac-specific genes and proteins were observed in order to determine the possible effects of oxidative stress on MSC function.

\section{Materials and methods}

Chemicals and reagents. Alizarin Red S (cat. no. 130-22-3), Oil Red O (cat. no. O0625), dexamethasone (cat. no. D4902), ascorbic acid (cat. no. 508107), $\beta$-glycerophosphate (cat. no. 35675) and MTT reagent (cat. no. M6494) were purchased from Sigma-Aldrich (Merck KGaA, Darmstadt, Germany). All antibodies for flow cytometry were supplied by BD PharmingenÔ (San Jose, CA, USA). Cell culture reagents, including Dulbecco's modified Eagle's medium (DMEM) (cat. no. $31600-034$ ), $0.25 \%$ trypsin-EDTA (cat. no. 25200-056), PenStrep (cat. no. 15140-122) and GlutaMAX (cat. no. 35050-061), were purchased from Gibco (Thermo Fisher Scientific, Inc., Waltham, MA, USA).

Isolation and expansion. MSCs derived from Wharton's jelly were collected from the umbilical cords of mothers after a full-term, healthy delivery ( $\mathrm{n}=6$; age of mother, $25-35$ years). This collection step and the informed consent process were approved by the Mahidol University Institutional Review Board (protocol no. 147.1311). Written informed consent was obtained from all participants. The umbilical cords were washed several times with PBS prior to cutting them into small pieces (length, $3 \mathrm{~cm}$ ). Each piece of Wharton's jelly was longitudinally cut for removal of all blood vessels. The matrix was scraped and minced into small pieces prior to digestion with $3 \mathrm{mg} / \mathrm{ml}$ collagenase type II (cat. no. 44S51434A; Worthington Biochemical Corp., Lakewood, NJ, USA) in DMEM for $1 \mathrm{~h}$ at $37^{\circ} \mathrm{C}$, following washing by centrifugation at $25^{\circ} \mathrm{C}, 2,000 \mathrm{xg}$ for $5 \mathrm{~min}$ and incubation with $0.25 \%$ trypsin-EDTA for $20 \mathrm{~min}$ at $37^{\circ} \mathrm{C}$. Following the trypsin digestion step, all samples were collected and washed twice by centrifugation at $25^{\circ} \mathrm{C}, 2,000 \mathrm{xg}$ for $5 \mathrm{~min}$ each. The pellet was re-suspended in complete medium consisting of low-glucose DMEM (DMEM-LG) supplemented with $10 \%$ fetal bovine serum (FBS; cat no. ES-009-V Merck KGaA, Darmstadt, Germany), 1\% PenStrep and 1\% GlutaMAX. The harvested cells were cultured at $37^{\circ} \mathrm{C}$ in $5 \% \mathrm{CO}_{2}$ and $95 \%$ humidified air. Non-adherent cells were removed after 3 days of culture and medium replacement was performed twice per week.

BM-MSCs were purchased from Merck KGaA (cat. no., SCC034 and lot no, 2460401). BM-MSCs were cultured in complete Dulbecco's modified Eagle's medium-low glucose (DMEM-LG) supplemented with $10 \%$ fetal bovine serum (FBS), $1 \%$ penicillin streptomycin and $1 \%$ GlutaMAX. After reaching $80 \%$ cell confluence, sub-passaging was performed using $0.25 \%$ trypsin-EDTA. WJ-MSCs and BM-MSCs at passage 4-7 were utilized in this study.

MSC characterization. WJ-MSCs and BM-MSCs were characterized following the minimal criteria for defining MSCs as outlined by the International Society for Cellular Therapy (17).

The differentiation of WJ-MSCs and BM-MSCs into adipocytes was performed according to the adipogenic differentiation protocol provided by the manufacturer. WJ-MSCs were seeded into $35-\mathrm{mm}$ dishes $\left(3 \times 10^{4}\right.$ cells per dish) with adipogenic differentiation medium (cat. no. 05403; Stem Cell Technologies, Vancouver, Canada) and cultured for 35 days. Differentiated cells were stained with Oil Red O. Briefly, Oil Red O staining was performed as follows: differentiated MSCs were rinsed with $1 \mathrm{X}$ phosphate buffered saline (PBS) twice and fixed with formalin vapour for $10 \mathrm{~min}$ at room temperature. MSCs were stained with $0.3 \%$ Oil Red O for 20 min at room temperature. Cells were washed twice and observed using light microscopy.

For osteogenic differentiation, WJ-MSCs and BM-MSCs were plated into $35-\mathrm{mm}$ dishes $\left(3 \times 10^{4}\right.$ cells per dish) with osteogenic differentiation medium (complete DMEM-LG, $0.1 \mu \mathrm{M}$ dexamethasone, $50 \mu \mathrm{g} / \mathrm{ml}$ ascorbic acid and $10 \mathrm{mM}$ $\beta$-glycerophosphate) and cultured for 35 days. Differentiated cells were stained with Alizarin Red S. In brief, the culture medium was discarded from the culture flask, and rinsed twice with $1 \mathrm{X}$ PBS. The differentiated cells were fixed with $10 \%$ formaldehyde for $15 \mathrm{~min}$ at room temperature. Cells were washed twice with distilled water (DW) followed by DW removal. A total of $40 \mathrm{mM}$ Alizarin red S (pH 4.1) was applied for $20 \mathrm{~min}$ with gentle agitation. All staining steps were performed at room temperature. The excess dye was removed and washed with DW three times. The samples were examined by inverted microscopy.

For flow cytometric studies of MSCs, WJ-MSCs and BM-MSCs were trypsinized for $5 \mathrm{~min}$ at $37^{\circ} \mathrm{C}$ to produce single-cell suspensions. The cell suspensions were collected and washed twice prior to resuspension in PBS containing $2 \%$ FBS and $1 \mathrm{mM}$ EDTA. Cells were adjusted to $1 \times 10^{6}$ in 
$100 \mu 1$ cells suspension. For cell surface labelling, cells suspensions were incubated at $4^{\circ} \mathrm{C}$ for 30 min with $5 \mu \mathrm{l}$ of antibodies (dilution, 1:20) against MSC-specific surface markers [phycoerythrin (PE)-conjugated mouse anti-human CD105 (cat. no. 560839), PE-Cy7-conjugated mouse anti-human CD73 (cat. no. 561258) and allophycocyanine-conjugated mouse anti-human CD90 (cat. no. 559869)] and hematopoietic stem cell (HSC)-specific markers [(PE-conjugated mouse anti-human CD34 (cat. no. 343606) and peridinin chlorophyll-conjugated mouse anti-human CD45 (cat. no. 304026)]. All antibodies were supplied by BD Pharmingen ${ }^{\mathrm{TM}}$ (San Jose, CA, USA). Cell surface marker analysis was performed by use of a BD FACSCanto ${ }^{\mathrm{TM}}$ II Flow Cytometer and FACSDIVA software version 6.1.3 (BD Biosciences, San Jose, CA, USA).

Cell viability assay. According to previous studies $(18,19)$, treatment with $100-2,000 \mu \mathrm{M} \mathrm{H}_{2} \mathrm{O}_{2}$ was able to influence the cellular senescence of MSCs. In a preliminary study performed by our group, MSCs were treated with 50, 100, 200, 500, 700 and $1,000 \mu \mathrm{M} \mathrm{H}_{2} \mathrm{O}_{2}$. There was no difference in the MTT results among the groups treated with 50,100 and $200 \mu \mathrm{M} \mathrm{H}_{2} \mathrm{O}_{2}$. Thus, $200 \mu \mathrm{M}$ was selected as the minimal dose of $\mathrm{H}_{2} \mathrm{O}_{2}$ in the present study. WJ-MSCs and BM-MSCs were seeded in 96-well plates at a density of $1 \times 10^{4}$ cells/well, and allowed to attach to the plastic surface. Wells were inoculated with various concentrations (200, 500 and $1,000 \mu \mathrm{M})$ of $\mathrm{H}_{2} \mathrm{O}_{2}$ (cat. no., 107209; Merck KGaA) in culture medium. All treatments for each time-point were performed in triplicate cell samples. After incubation for 24,48 or $72 \mathrm{~h}, 50 \mu \mathrm{l}$ MTT reagent was applied. MTT was reduced by succinate dehydrogenase enzyme into an insoluble formazan crystal product. The intracellular crystals were solubilized by dimethyl sulfoxide (cat. no., 2743C104; Amresco, Solon, OH, USA) and the absorbance was measured at $570 \mathrm{~nm}$. The absorbance values were then recorded and compared with those of the control cells.

Analysis of the effect of $\mathrm{H}_{2} \mathrm{O}_{2}$ on cardiogenic differentiation of WJ-MSCs. To study the effect of $\mathrm{H}_{2} \mathrm{O}_{2}$ on the cardiogenic differentiation of MSCs, they were treated with 5-azacytidine followed by various doses of $\mathrm{H}_{2} \mathrm{O}_{2}$ (20). Cardiomyocyte differentiation was initiated by treatment with $10 \mu \mathrm{M} 5$-azacytidine for $24 \mathrm{~h}$ followed by different doses of $\mathrm{H}_{2} \mathrm{O}_{2}$ for $24 \mathrm{~h}$. The short-term effect on cardiogenic markers was observed at days 3 and 7 after treatment with $\mathrm{H}_{2} \mathrm{O}_{2}$. These optimized time-points were selected because the properties of MSCs dedifferentiate after day 7 (data not shown). WJ-MSCs and BM-MSCs were plated in culture vessels and incubated overnight. Complete DMEM supplemented with $10 \mu \mathrm{M} 5$-azacytidine was applied to adherent cells for $24 \mathrm{~h}$. The medium containing 5-azacytidine was then removed, and the cells were washed twice with DMEM-LG. Complete DMEM supplemented with 200, 500 or $1,000 \mu \mathrm{M} \mathrm{H}_{2} \mathrm{O}_{2}$ was applied for $24 \mathrm{~h}$ prior to washing twice and replacement with fresh complete medium. Treated WJ-MSCs and BM-MSCs were maintained in culture for further detection of cardiogenic marker expression on days 3 and 7.

Reverse-transcription quantitative polymerase chain reaction (RT-qPCR) analysis of cardiac-specific genes. RNA was collected using TRIzol ${ }^{\circledR}$ reagent (cat. no., 15596026; Invitrogen; Thermo Fisher Scientific, Inc., Waltham, MA, USA) and isolated using Direct-zol columns (cat. no., R2050; Zymo
Research, Irvine, CA, USA), following the manufacturer's instructions. Quantification of RNA was performed with a Nanodrop 2000 ultraviolet-vis spectrophotometer (Thermo Fisher Scientific, Inc.). RNA ( $2 \mu \mathrm{g} / \mathrm{sample})$ was converted to complementary DNA using Sensiscript Reverse Transcription kits (cat. no., 205211; Qiagen, Valencia, CA, USA). To study cardiogenic genes, qPCR was performed with SYBR Green Supermix (cat. no., 170-8880; Bio-Rad Laboratories, Inc., Hercules, CA, USA), according to the manufacturer's instructions. The PCR mixture was composed of $12.5 \mu 1$ of $\mathrm{iQ}^{\mathrm{TM}}$ SYBR $^{\circledast}$ Green Supermix, $0.5 \mu \mathrm{l}$ of $10 \mu \mathrm{M}$ forward primer, $0.5 \mu \mathrm{l}$ of $10 \mu \mathrm{M}$ reverse primer $5.5 \mathrm{ml}$ of nuclease-free water and $1 \mu \mathrm{l}$ of cDNA $(100 \mathrm{ng} / \mu \mathrm{l})$. The detection was performed with a CFX96 Real-Time PCR platform (Bio-Rad Laboratories, Inc.). The PCRs were performed in duplicate and conditions were as follows: $95^{\circ} \mathrm{C}$ for $3 \mathrm{~min}$; followed by 40 cycles of $95^{\circ} \mathrm{C}$ for $3 \mathrm{sec}$ (denaturation), $60^{\circ} \mathrm{C}$ for $30 \mathrm{sec}$ (annealing temperature) and $72^{\circ} \mathrm{C}$ for $45 \mathrm{sec}$ (elongation); and $72^{\circ} \mathrm{C}$ for $5 \mathrm{~min}$. The primers were as follows: $\mathrm{Nkx} 2.5$ forward, $5^{\prime}-\mathrm{CTGCCGCCGC}$ CAACAAC-3' and reverse, 5'-CGCGGGTCCCTTCCCTAC CA-3'; cardiac troponin T (cTnT) forward, 5'-AGAGCGGAAA AGTGGGAAGA-3' and reverse, 5'-CTGGTTATCGTTGATC CTGT-3'; and cardiac $\alpha$-actin forward, 5'-TCTATGAGGGCT ACGCTTTG-3' and reverse, 5'-GCCAATAGTGATGACTTG GC-3'; GAPDH forward, 5'-CAACTACATGGTTTACATGTT CCAA-3' and reverse, 5'-CAGCCTTCTCCATGGTGGT-3'. The levels of the cardiac-specific genes (Nkx2.5, cTnT and cardiac $\alpha$-actin) were analyzed using Bio-Rad CFX Manager version 3.1 (Bio-Rad Laboratories, Inc.) and normalized to the level of GAPDH (21).

Immunofluorescence staining. Treated WJ-MSCs and BM-MSCs were fixed with $4 \%$ paraformaldehyde prior to being washed twice with PBS. Permeabilization was performed using $0.3 \%$ Triton X (cat. no. 9002931; Merck KGaA). Prior to staining with primary antibodies, cells were non-specifically blocked with $3 \%$ bovine serum albumin (cat. no. A7906; Invitrogen; Thermo Fisher Scientific, Inc.). Subsequently, cells were incubated overnight at $4^{\circ} \mathrm{C}$ with anti-GATA4 (cat. no. sc-25310; Santa Cruz Biotechnologies, Inc., Danvers, TX, CA, USA) and anti-cTnT (cat. no. MAB1693; Merck KGaA) antibodies (1:100 dilution). Cells were washed with PBS prior to incubation with Alexa Fluor ${ }^{\circledR} 568$-conjugated goat anti-mouse immunoglobulin antibodies (cat. no. A-11004; Invitrogen; Thermo Fisher Scientific, Inc.) and fluorescein isothiocyanate (FITC)-conjugated rabbit anti-mouse immunoglobulin antibodies (cat. no. F0232; Dako Cytomation, Tokyo, Japan) for $45 \mathrm{~min}$ at room temperature. Cells were washed twice with PBS prior to mounting with ProLong ${ }^{\circledR}$ Gold Antifade Mountant with DAPI solution (cat no. P36941; Invitrogen; Thermo Fisher Scientific, Inc.,). The fluorescent micrographs were captured using a confocal laser scanning microscope and analyzed with FluoView FV1000 Software version 3.01 (Olympus Corp., Tokyo, Japan). To evaluate fluorescence intensity, the micrographs captured at a magnification of $x 40$ were equally divided into 9 areas, and 5 counting areas ( 4 corner squares and 1 center square) were selected as regions of interest (ROIs) for subsequent study. Only positively stained cells in the ROIs were quantified for fluorescence intensity measurements $(22,23)$. 

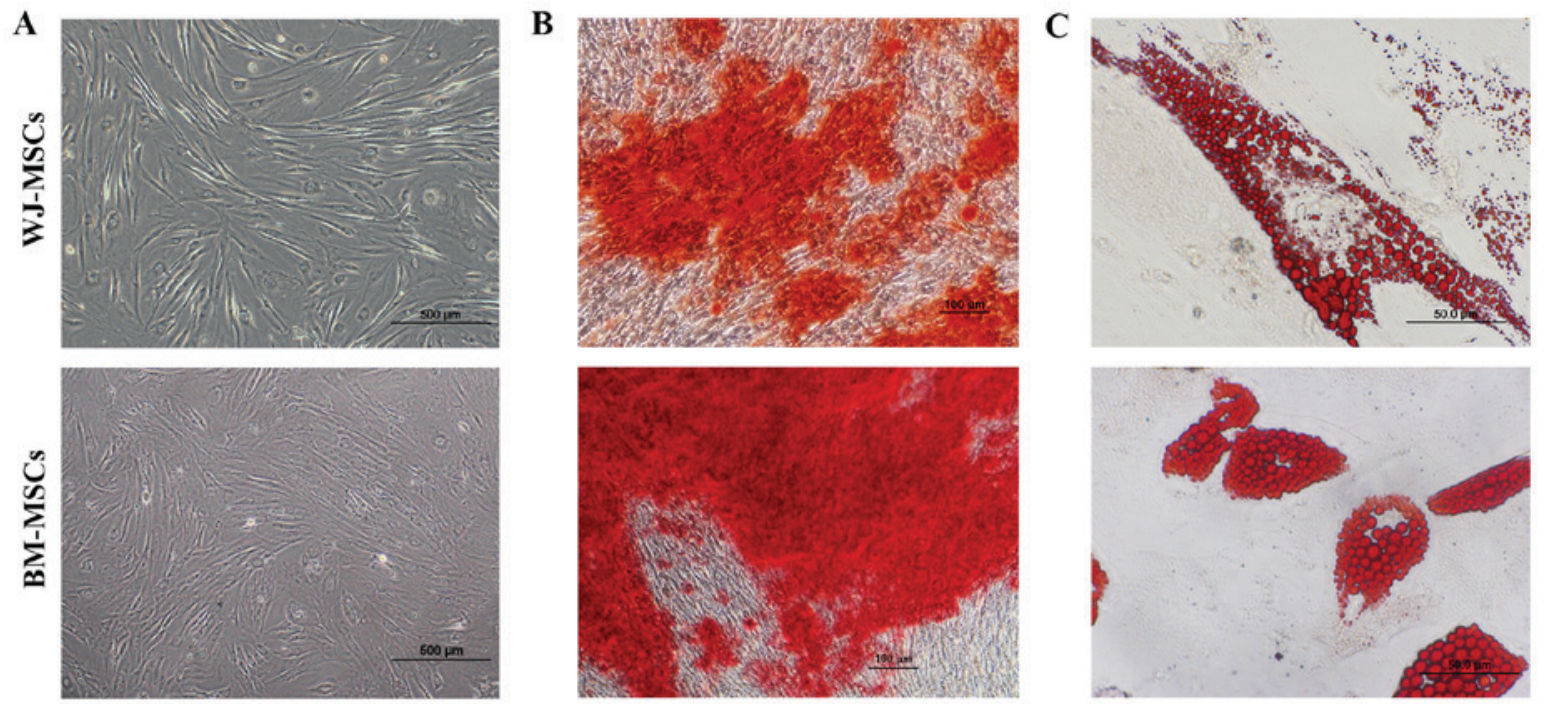

D
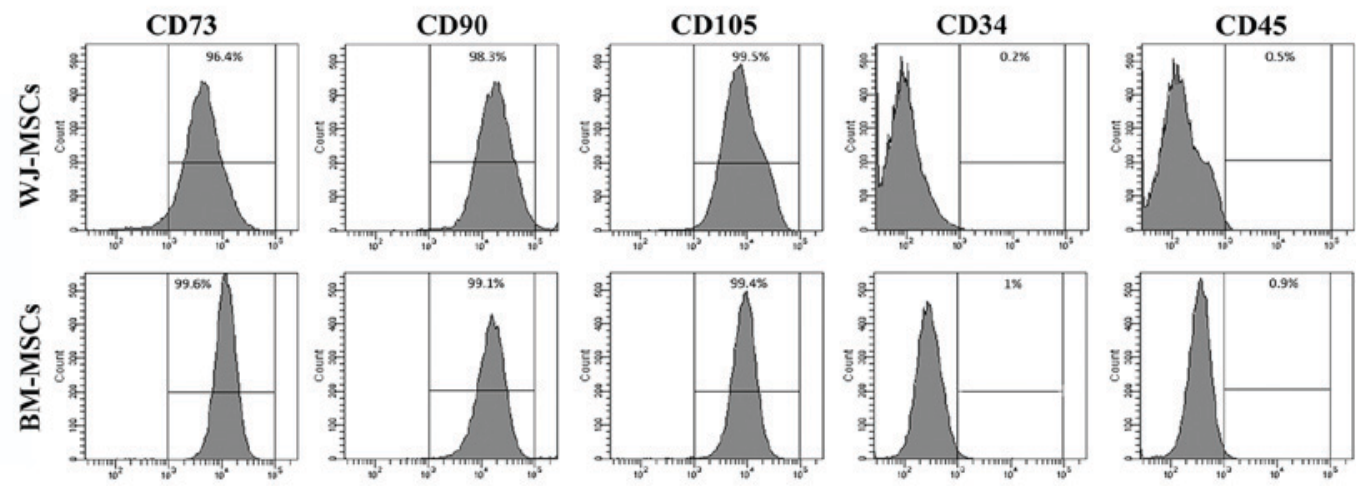

Figure 1. (A) Images of enzymatically disaggregated Wharton's jelly-derived cells in primary culture displaying their fibroblastoid shape, similar to that of BM-MSCs (scale bars, $500 \mu \mathrm{m}$ ). (B and C) Mesodermal differentiation of MSCs into osteoblasts and adipocytes was performed. (B) BM-MSCs and WJ-MSCs cultured in osteogenic differentiation medium for 35 days displayed positive Alizarin Red S staining, indicating osteoblastic differentiation (scale bars, $100 \mu \mathrm{m}$ ). (C) BM-MSCs and WJ-MSCs cultured in adipogenic differentiation medium for 35 days were positive for Oil Red O staining, indicating adipogenic differentiation (scale bars, $50 \mu \mathrm{m}$ ). (D) Flow cytometric analysis of MSC surface markers indicated reactivity for CD73, CD90 and CD105, and no reactivity for CD34 and CD45. BM-MSCs, bone marrow-derived mesenchymal stem cells; WJ-MSCs, Wharton's jelly-derived MSCs.

Statistical analysis. WJ-MSCs from 6 donors were performed independently $(n=6)$ all values were expressed as the mean \pm standard error of the mean. Statistical analysis was performed using PASW Statistics version 18 (IBM Corp., Armonk, NY, USA). The Mann-Whitney U test was used to analyze differences between groups. $\mathrm{P}<0.05$ was considered to indicate a statistically significant difference.

\section{Results}

Characterization of MSCs. WJ-MSCs were isolated from Wharton's jelly; the cells usually grew from the cell cluster after 3 days of culture. WJ-MSCs and BM-MSCs exhibited a fibroblast-like morphology and a high level of adherence to the plastic culture flasks (Fig. 1A). Characterization of the MSCs was subsequently performed.

For osteogenic and adipogenic differentiation, MSCs were cultured with osteogenic and adipogenic differentiation medium, respectively, for 5 weeks. Under osteogenic differentiation conditions, the morphology of the MSCs became osteoblast-like with matrix accumulation (Fig. 1B). In MSCs cultured in adipogenic differentiation medium, fat droplet-containing cells were observed (Fig. 1C). Cytochemical staining with Alizarin Red
$\mathrm{S}$ and Oil Red O indicated differentiation into osteoblast-like and adipocyte-like cells, respectively.

The analysis of specific cell surface markers revealed that MSCs at passage 4 exhibited high rates of positive staining for CD73 (99.3 $\pm 0.4 \%), C D 90(96.9 \pm 1.1 \%)$ and CD105 (99.9 $\pm 0.4 \%)$, but were mostly negative for the hematopoietic markers CD34 $(1 \pm 0.3 \%)$ and $\mathrm{CD} 45(1.3 \pm 0.6 \%)$ (Fig. 1D).

Viability of MSCs after treatment with $\mathrm{H}_{2} \mathrm{O}_{2}$. The effect of $\mathrm{H}_{2} \mathrm{O}_{2}$ on the viability of MSCs was investigated. MSCs treated with $\mathrm{H}_{2} \mathrm{O}_{2}$ alone and compared with the control $\left(\right.$ no $\mathrm{H}_{2} \mathrm{O}_{2}$ treatment using an MTT assay. The absorbance was measured at 24,48 and $72 \mathrm{~h}$. The absorbance ratios of control vs. treated cells were used for the calculation of the percent viability. The viability of WJ-MSCs after treatment with $\mathrm{H}_{2} \mathrm{O}_{2}$ was decreased in a dose- and time-dependent manner (Fig. 2A). The viability of BM-MSCs was only slightly decreased after treatment with 200 and $500 \mu \mathrm{M} \mathrm{H}_{2} \mathrm{O}_{2}$, but significantly decreased after treatment with $1,000 \mu \mathrm{M} \mathrm{H}_{2} \mathrm{O}_{2}$ (Fig. 2B).

Effect of $\mathrm{H}_{2} \mathrm{O}_{2}$ on MSC morphology and cardiac-specific marker expression. The morphology and cardiomyocyte differentiation of MSCs were observed after treatment with 
A

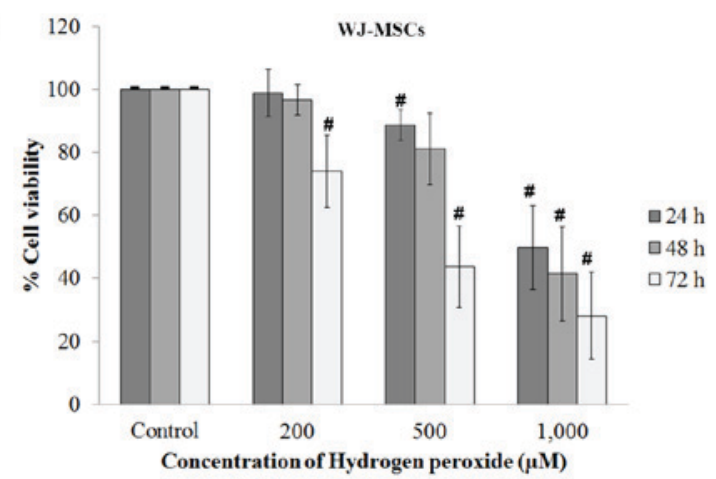

B

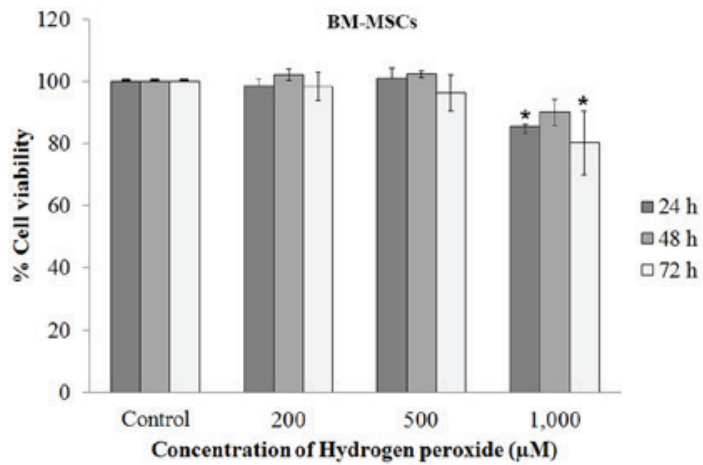

Figure 2. The viability was evaluated in MSCs treated with $\mathrm{H}_{2} \mathrm{O}_{2}$ alone comparison with the control (no $\mathrm{H}_{2} \mathrm{O}_{2}$ treatment). MSCs were treated with $\mathrm{H}_{2} \mathrm{O}_{2}$ $(200,500$ or $1,000 \mu \mathrm{M})$ at 24,48 and $72 \mathrm{~h}$. (A) The viability of WJ-MSCs relative to that of the control cells was reduced by $\mathrm{H}_{2} \mathrm{O}_{2}$ treatment in a dose-dependent manner. (B) The viability of BM-MSCs differed from that of control cells only after treatment with 1,000 $\mu \mathrm{M} \mathrm{H}_{2} \mathrm{O}_{2}$. Values are expressed as the mean \pm standard error of the mean of six separate experiments performed in triplicate in WJ-MSCs and three separate experiments performed in triplicate in BM-MSCs. ${ }^{\#,} \mathrm{P}<0.05$ vs. control group for WJ-MSCs or BM-MSCs, respectively. BM-MSCs, bone marrow-derived mesenchymal stem cells; WJ-MSCs, Wharton's jelly-derived MSCs.

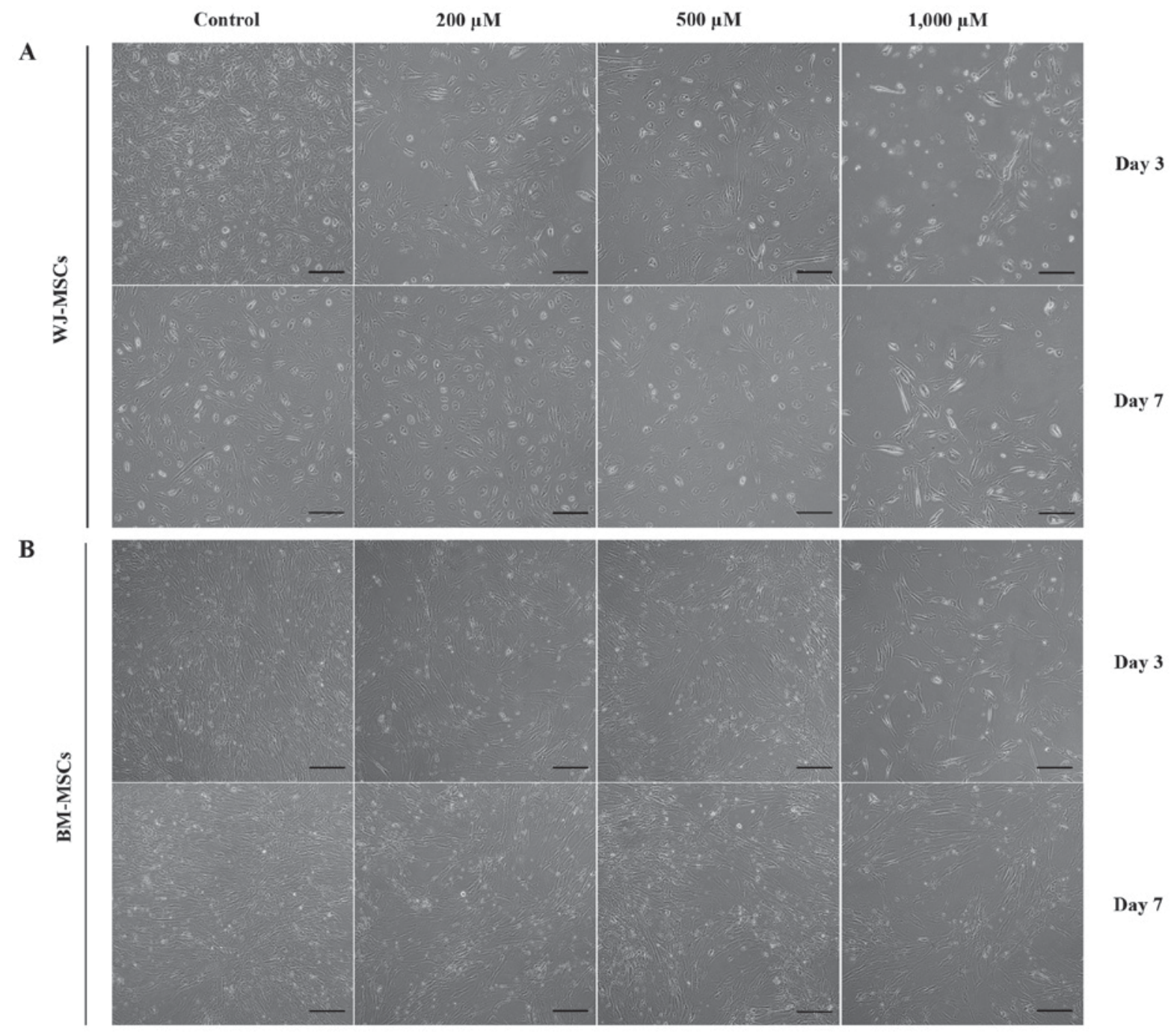

Figure 3. Phase contrast microscopy images of MSCs following treatment with $\mathrm{H}_{2} \mathrm{O}_{2}$ alone for 3 and 7 days. (A) WJ-MSCs treated with different doses of $\mathrm{H}_{2} \mathrm{O}_{2}$ (200, 500 or $1,000 \mu \mathrm{M}$ ) exhibited a lower cellular density than the control group (no $\mathrm{H}_{2} \mathrm{O}_{2}$ treatment). (B) BM-MSCs treated with different doses of $\mathrm{H}_{2} \mathrm{O}_{2}(200$, 500 or $1,000 \mu \mathrm{M}$ ) exhibited a lower cellular density than the control group (scale bar, $200 \mu \mathrm{M}$ ). BM-MSCs, bone marrow-derived mesenchymal stem cells; WJ-MSCs, Wharton's jelly-derived MSCs.

5-azacytidine with and without $\mathrm{H}_{2} \mathrm{O}_{2}(200,500$ and 1,000 $\mu \mathrm{M})$. Cells in all treatment groups appeared similar, with a fibroblastoid shape. However, the cell density was attenuated by treatment with increasing $\mathrm{H}_{2} \mathrm{O}_{2}$ concentrations (Fig. 3). 
A

$\underset{\text { Day -3 }}{\substack{\text { MSCs } \\ \text { Seeding }}}$

WJ-MSCs

B

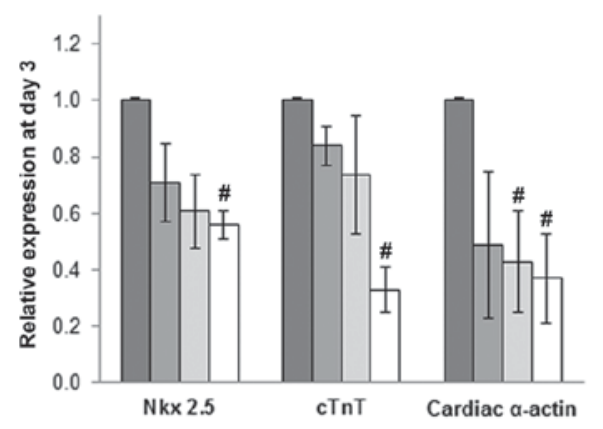

C

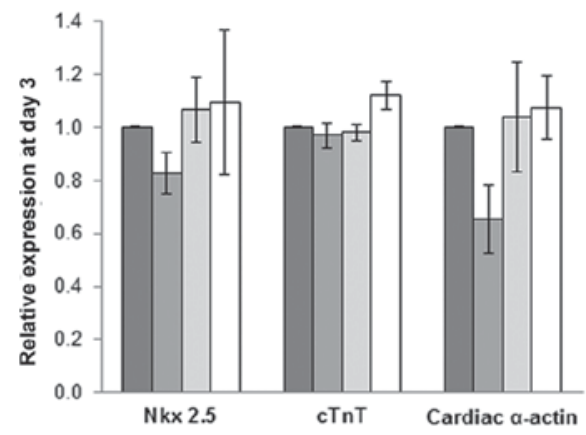

口Untreated $\square 200 \mu \mathrm{M}$ $\square 500 \mu \mathrm{M}$ $\square 1,000 \mu \mathrm{M}$

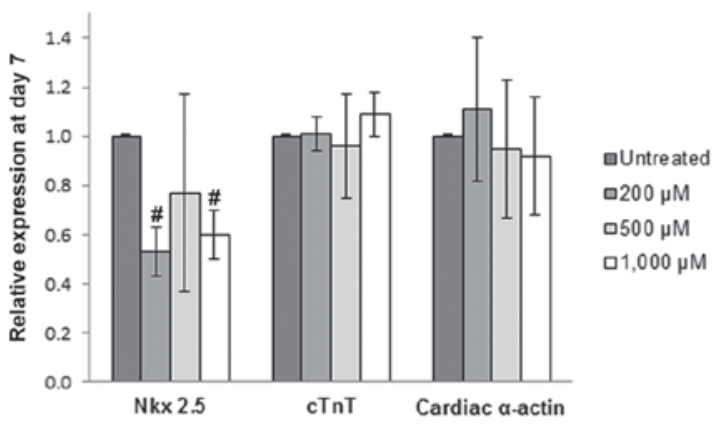

BM-MSCs

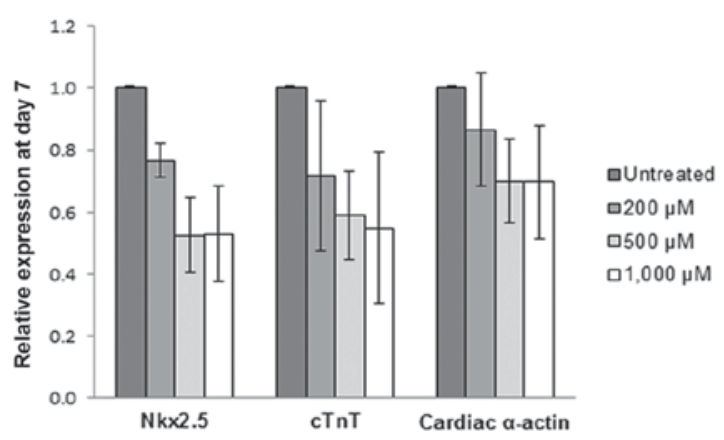

Figure 4. (A) Schematic diagram representing the process used to study the cardiomyocyte differentiation of MSCs using 5-azacytidine and hydrogen peroxide. (B) Cardiac-specific gene expression in WJ-MSCs after treatment for 3 and 7 days. The levels of Nkx 2.5 , cTnT and cardiac $\alpha$-actin were significantly reduced after treatment for 3 days compared with untreated cells (MSCs treated with 5-azacytidine to make them differentiate into cardiomyocytes, but not with $\mathrm{H}_{2} \mathrm{O}_{2}$ ), and these expression levels recovered after culture for 7 days. In BM-MSCs, the relative expression levels of cardiac-specific markers after treatment were decreased compared with those of untreated cells only after culture for 7 days $(\mathrm{C})$. Values are expressed as the mean \pm standard error of the mean of six separate experiments performed in duplicate in WJ-MSCs and three separate experiments performed in duplicate in BM-MSCs. ${ }^{*} \mathrm{P}<0.05$ vs. untreated cells for WJ-MSCs or BM-MSCs, respectively. BM-MSCs, bone marrow-derived mesenchymal stem cells; WJ-MSCs, Wharton's jelly-derived MSCs; DMEM-LG, low-glucose Dulbecco's modified Eagle's medium; FBS, fetal bovine serum; cTnT, cardiac troponin T.

Quantitative analysis of the mRNA expression levels of cardiac-specific genes (Nkx2.5, cTnT and $\alpha$-cardiac actin) was performed by RT-qPCR. After culture for 3 days as illustrated in Fig. 4A, the expression of Nkx2.5, cTnT and cardiac $\alpha$-actin in 5-azacytidine-treated MSCs was reduced in a dose-dependent manner following treatment with $\mathrm{H}_{2} \mathrm{O}_{2}(200$, 500 or $1,000 \mu \mathrm{M})$. The gene expression levels then recovered and returned almost to the expression levels of the untreated cells. The recovery of gene expression was observed in treated cells after culture at day 7 (Fig. 4B and C).

MSCs were exposed to $10 \mu \mathrm{M}$ of 5-azacytidine and treated with 200,500 or $1,000 \mu \mathrm{M} \mathrm{H}_{2} \mathrm{O}_{2}$ for $24 \mathrm{~h}$. The differentiated cells were stained with antibodies against GATA4 (labelled with Alexa Fluor 568) and cTnT (labelled with FITC). Immunofluorescent micrographs of WJ-MSCs (Fig. 5A) and BM-MSCs (Fig. 5B) were captured and analyzed to assess the fluorescence intensity (using ROIs) at days 3 and 7 which was presented in Fig. 6.

Following treatment with $\mathrm{H}_{2} \mathrm{O}_{2}$, the fluorescence intensity of GATA4 in BM-MSCs and WJ-MSCs was dose-dependently decreased compared with that in untreated cells (Fig. 6A and C). Similarly, the fluorescence intensity of cTnT in $\mathrm{H}_{2} \mathrm{O}_{2}$.treated WJ-MSCs was decreased after culture for 3 and 7 days, and was significantly different from that of untreated cells. In BM-MSCs, a significant decrease of cTnT fluorescence intensity was only observed after treatment for 7 days (Fig. 6B and D).

\section{Discussion}

Stem cell therapy is a novel and promising method for treating degenerative disorders. One of the most interesting therapeutic applications is MSC transplantation in IHD. Previous studies 


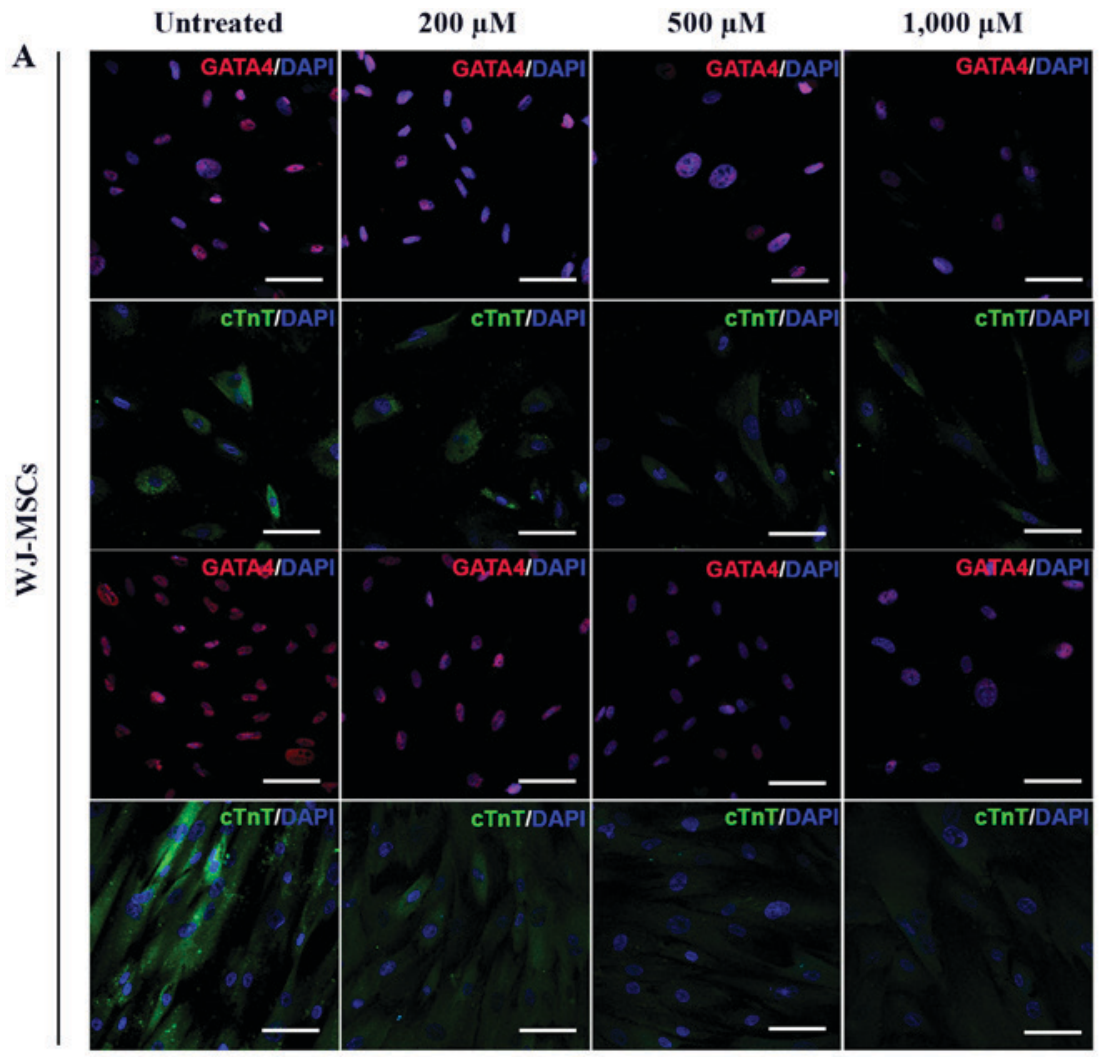

Day 3

B
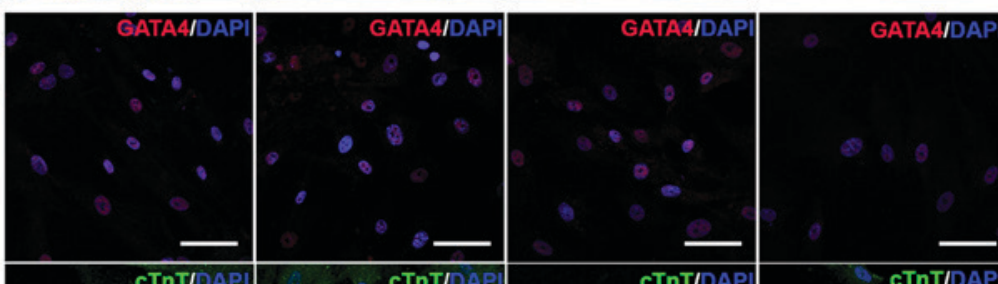

GATA 4 ILAR

Day 3

Day 7

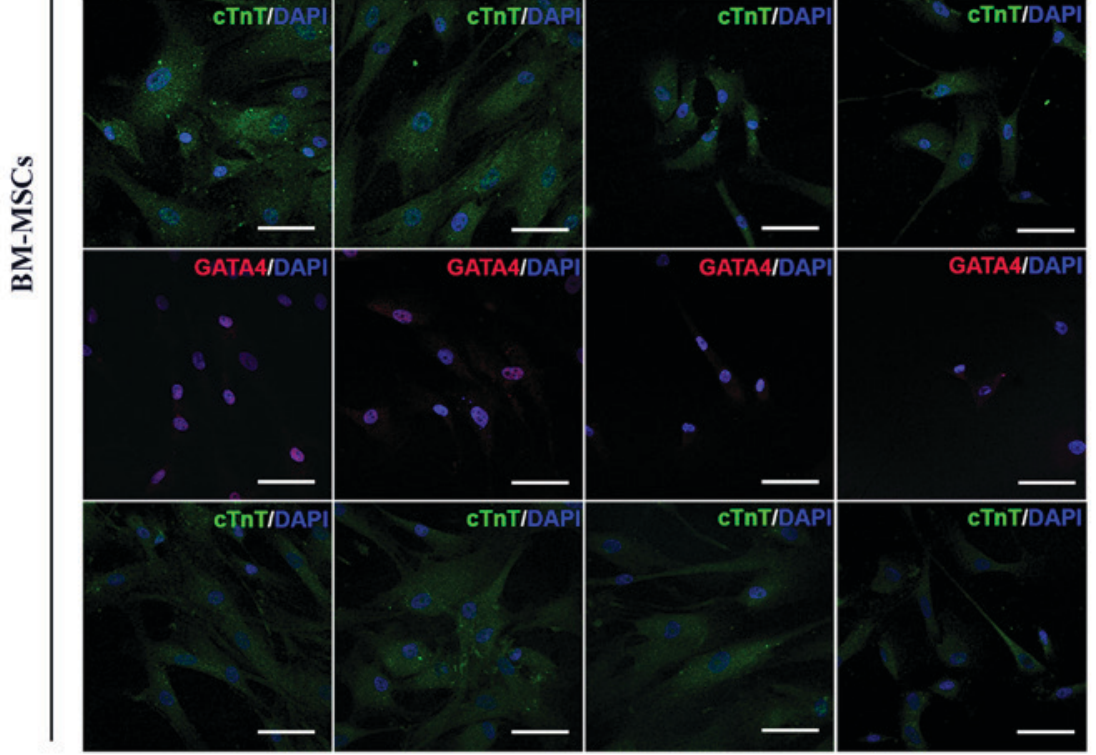

Day 7

Figure 5. Immunofluorescence micrographs of the cardiac-specific proteins GATA4 and cTnT in 5-azacytidine-treated (A) WJ-MSCs and (B) BM-MSCs with or without $\mathrm{H}_{2} \mathrm{O}_{2}$ treatment (scale bars, $100 \mu \mathrm{M}$ ). Lower fluorescence intensities of the two markers were observed in $\mathrm{H}_{2} \mathrm{O}_{2}$-treated cells compared with untreated cells. BM-MSCs, bone marrow-derived mesenchymal stem cells; WJ-MSCs, Wharton's jelly-derived MSCs; cTnT, cardiac troponin T.

have demonstrated that the IHD conditions trigger the death of cardiomyocytes due to the presence of excessive ROS in the infarct area. This results in premature senescence (24), apoptosis (14), impairment of immunomodulatory function (25) and fibrous tissue formation (26). Stem cell transplantation approaches for the treatment of cardiac injury have been investigated in several animal studies and clinical trials $(27,28)$. The efficacy of MSC transplantation depends on the survival and differentiation ability of MSCs and their role in the recovery of cardiac function $(25,26)$. The rate of successful transplantation 
A

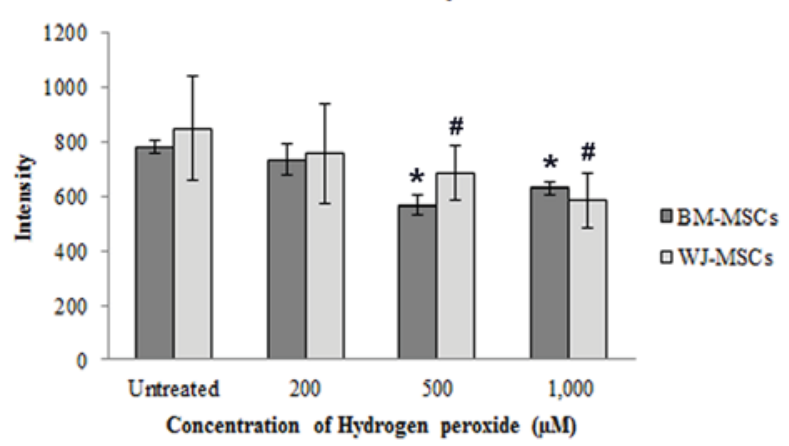

C

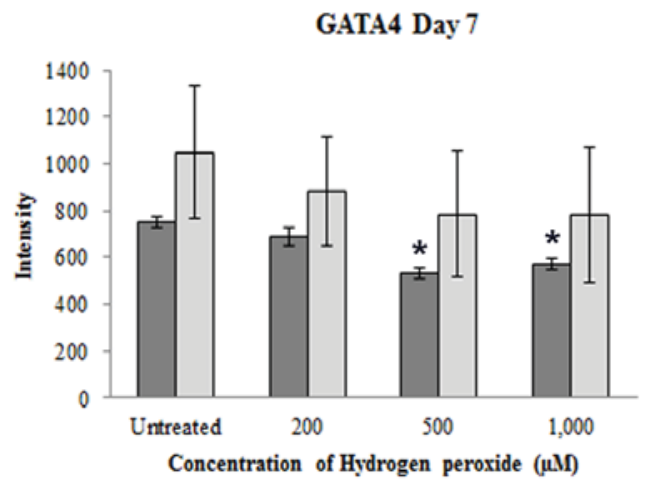

B

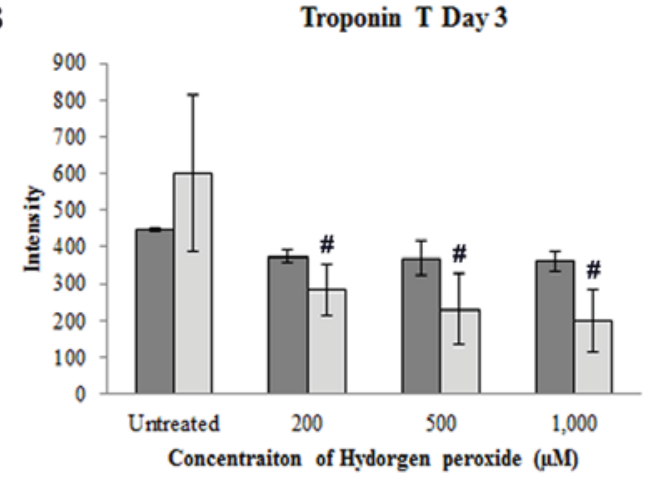

D

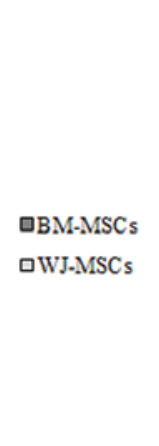

Troponin T Day 7

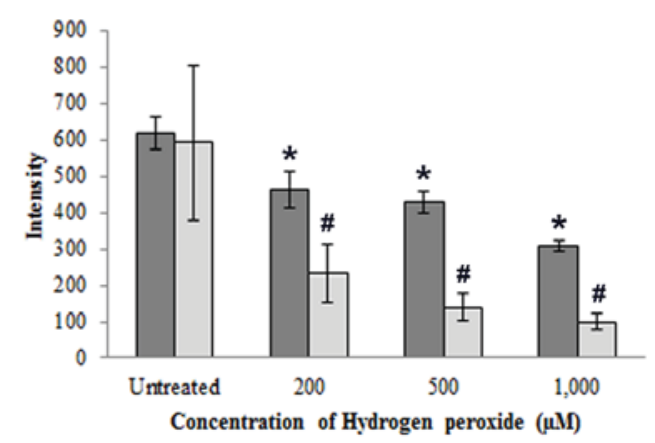

口BM-MSCs 口WJ-MSCs

口BM-MSCs 口WJ-MSCs

Figure 6. Fluorescence intensities of (A) GATA4 and (B) cTnT on day 3 as well as (C) GATA4 and (D) cTnT on day 7 were decreased after exposure to hydrogen peroxide $(200,500$ or $1,000 \mu \mathrm{M})$ when compared with that in untreated cells at the same time-points. Values are expressed as the mean \pm standard error of the mean of six separate experiments performed in WJ-MSCs and three separate experiments performed in BM-MSCs. \#,* $<0.05$ vs. untreated cells for WJ-MSCs or BM-MSCs, respectively. BM-MSCs, bone marrow-derived mesenchymal stem cells; WJ-MSCs, Wharton's jelly-derived MSCs; cTnT, cardiac troponin T.

outcomes remains low, likely due to the effect of residual oxidative stress on the transplanted cells in damaged tissues (15). However, the underlying mechanisms of this inefficiency have remained to be fully elucidated.

In the present study, the effect of ROS on one particular function of MSCs, namely cardiomyocyte differentiation, was evaluated. The characteristics of WJ-MSCs and BM-MSCs were assessed, which revealed that MSCs from each of these two sources exhibited the same characteristics, in that they were positive for Oil Red O and Alizarin Red S staining after induction of adipogenic and osteogenic differentiation, respectively. Mesenchymal surface markers (CD90, CD73 and CD105) were present on MSCs from each of the two sources (>95\% of cells), whereas they were mostly negative for HSC markers $(<2 \%$ of cells), which was in accordance with previous studies (29). WJ-MSCs and BM-MSCs were cultured under stress conditions to evaluate their survivability. The viability of only the WJ-MSCs was demonstrated to be significantly reduced by $\mathrm{H}_{2} \mathrm{O}_{2}$ in a dose- and time-dependent manner. This suggested that BM-MSCs may have higher resistance to ROS compared with WJ-MSCs. Under stress conditions, this property may be modulated in BM-MSCs via the release of hydrogen peroxide-scavenging enzymes, such as superoxide dismutase, catalase and glutathione peroxidase, providing resistance to oxidative stress-induced cell death (30). However, studies on the effects of ROS on MSCs of different origin have yielded controversial and inconclusive results. Certain studies suggested that WJ is an optimal source of MSCs due WJ-MSCs having a higher potential for proliferation (31) and differentiation (32) than other types of MSCs, such as BM-MSCs. This was supported by the fact that WJ-MSCs had higher expression levels of several cell cycle-associated genes, including cyclin (CCN)D2, cell division cycle (CDC)25A, CCNA2, CCNB1, CDC28, cyclin-dependent kinases (CDK) regulatory subunit $2, \mathrm{CDC} 25 \mathrm{C}, \mathrm{CDC} 20$ and aurora $\mathrm{B}$ kinase, compared with the levels in BM-MSCs. These genes promote the cell cycle transition from $\mathrm{S}$ to $\mathrm{G} 2 / \mathrm{M}$ phase. By contrast, compared with WJ-MSCs, BM-MSCs exhibit increased expression levels of B-cell lymphoma 2 and CDK inhibitor $1 \mathrm{~B}$, which mediate delayed transition into $\mathrm{S}$ phase (33). These findings implied that endogenous differences between MSC sources may lead to different responses between BM-MSCs and WJ-MSCs. Therefore, further studies should be performed to prove that the different properties of MSCs depend on their origin.

MSCs originating outside of the bone marrow appear to manage oxidative stress differently; they may resist oxidative insults to a greater extent than normal somatic cells, such as fibroblasts (34). For instance, Ertaş et al (35) identified that BM-MSCs and adipose-derived MSCs possessed higher resistance to $\mathrm{H}_{2} \mathrm{O}_{2}$-induced apoptosis, but had a greater tolerance for $\mathrm{H}_{2} \mathrm{O}_{2}$ compared with BM-MSCs. The underlying mechanisms of these anti-oxidant properties are largely unknown. Release of extracellular vesicles from WJ-MSCs may be an important mechanism, as reported by Zhang et al (36), who demonstrated that WJ-MSCs cultured in conditioning medium may improve the function of kidney cells and decrease apoptosis following acute renal injury. In that study, the extracellular 
vesicles isolated from the conditioning medium attenuated oxidative damage in injured kidney tissue, and this antioxidant effect was demonstrated to result from nuclear erythroid 2-related factor 2/antioxidant responsive element activation. Pre-conditioning of WJ-MSCs with $200 \mu \mathrm{M} \mathrm{H}_{2} \mathrm{O}_{2}$ in vitro promoted the expression of interleukin- 6 , leading to increased migration, proliferation and neovascularization properties of endothelial cells. A previous animal study also revealed that the infusion of $\mathrm{H}_{2} \mathrm{O}_{2}$-pre-conditioned WJ-MSCs in to the tail vein significantly enhances myocardial contractility (37).

In the present study, the cardiogenic differentiation of BM-MSCs and WJ-MSCs was evaluated under normal conditions and in the presence of ROS. The RNA expression of cardiogenesis-associated genes $(\mathrm{Nkx} 2.5$, cTnT and cardiac $\alpha$-actin) and proteins (GATA4 and cTnT), which contribute to cell fate in the early development of cardiomyocytes (38), were identified to rapidly decrease in WJ-MSCs following exposure to $\mathrm{H}_{2} \mathrm{O}_{2}$, and then recover by day 7. In BM-MSCs, a reduction in GATA4 expression was detected on day 3 and day 7; however, in cTnT expression, reduction in expression was detected only on day 7. In vitro studies of the effect of ROS on MSCs have frequently reported that ROS acts to promote cell growth inhibition (39), apoptosis (40) and premature senescence (41). The effect of ROS on differentiation capacity has also been reported in other cell types, such as osteoblasts (42). In a previous study, ROS had a different impact on BM-MSCs and WJ-MSCs, but the underlying mechanisms remained elusive (43). WJ-MSCs had certain advantages as a cell therapy for myocardial injury over adult or fetal BM-MSCs. Furthermore, the in vivo transplantation of WJ-MSCs was demonstrated to have a high potential for homing to infarcted myocardium and decreasing tissue damage (43). Thus, the type of MSCs used for transplantation must be selected with awareness of the specific aim; MSCs from different origins have similar but varying characteristics, and these distinctions must be considered to optimize the outcome of transplantation.

Transplantation efficiency is currently under extensive study for the purpose of identifying strategies for improvement. The concept of cell death prevention has been widely explored based on several concepts. Overexpression of antioxidants was considered to be highly promising, but the results are controversial; although high ROS levels cause cellular damage and dysfunction, it is thought that a low basal level of ROS is necessary and advantageous for maintaining cellular proliferation, differentiation and survival. ROS also has an important role in the post-infarction healing process by augmenting inflammation and tissue repair through the release of proteolytic enzymes, cytokines and growth factors $(44,45)$. Therefore, understanding the effects of ROS on stem cell behaviour is important and requires further study to allow for improvement of stem cell transplantation outcomes.

In conclusion, the present study suggested that the differentiation potency of MSCs of different origin may be helpful for selecting suitable cell sources to obtain better outcomes. Improvement of the selection of cells used for transplantation may be achieved through enhancing the current understanding of the underlying mechanisms of how MSCs respond to ROS. Comparing different abilities of WJ-MSCs and BM-MSCs in in vitro studies will help in selecting the optimal cell source for clinical trials.

\section{Acknowledgements}

The present study was supported by a research grant from Mahidol University (2556-2559 B.E.).

\section{References}

1. McAloon CJ, Boylan LM, Hamborg T, Stallard N, Osman F, Lim PB and Hayat SA: The changing face of cardiovascular disease 2000-2012: An analysis of the world health organisation global health estimates data. Int J Cardiol 224: 256-264, 2016.

2. von Harsdorf R, Li PF and Dietz R: Signaling pathways in reactive oxygen species-induced cardiomyocyte apoptosis. Circulation 99: 2934-2941, 1999.

3. Xu Z, Park SS, Mueller RA, Bagnell RC, Patterson C and Boysen PG: Adenosine produces nitric oxide and prevents mitochondrial oxidant damage in rat cardiomyocytes. Cardiovasc Res 65: 803-812, 2005.

4. Tao L, Gao E, Jiao X, Yuan Y, Li S, Christopher TA, Lopez BL, Koch W, Chan L, Goldstein BJ and Ma XL: Adiponectin cardioprotection after myocardial ischemia/reperfusion involves the reduction of oxidative/nitrative stress. Circulation 115: 1408-1416, 2007.

5. Bernstein HS and Srivastava D: Stem cell therapy for cardiac disease. Pediatr Res 71: 491-499, 2012.

6. Gao LR, Zhang NK, Ding QA, Chen HY, Hu X, Jiang S, Li TC, Chen Y, Wang ZG, Ye Y and Zhu ZM: Common expression of stemness molecular markers and early cardiac transcription factors in human Wharton's jelly-derived mesenchymal stem cells and embryonic stem cells. Cell Transplant 22: 1883-1900, 2013.

7. Li Q, Han SM, Song WJ, Park SC, Ryu MO and Youn HY: Anti-inflammatory effects of Oct4/Sox2-overexpressing human adipose tissue-derived mesenchymal stem cells. In Vivo 31: 349-356, 2017.

8. Shahini A, Mistriotis P, Asmani M, Zhao R and Andreadis ST: NANOG restores contractility of mesenchymal stem cell-based senescent microtissues. Tissue Eng Part A 23: 535-545, 2017.

9. Zhou C, Yang B, Tian Y, Jiao H, Zheng W, Wang J and Guan F: Immunomodulatory effect of human umbilical cord Wharton's jelly-derived mesenchymal stem cells on lymphocytes. Cell Immunol 272: 33-38, 2011.

10. Baksh D, Yao R and Tuan RS: Comparison of proliferative and multilineage differentiation potential of human mesenchymal stem cells derived from umbilical cord and bone marrow. Stem Cells 25: 1384-1392, 2007.

11. Ng F, Boucher S, Koh S, Sastry KS, Chase L, Lakshmipathy U, Choong C, Yang Z, Vemuri MC, Rao MS and Tanavde V: PDGF, TGF-beta, and FGF signaling is important for differentiation and growth of mesenchymal stem cells (MSCs): Transcriptional profiling can identify markers and signaling pathways important in differentiation of MSCs into adipogenic, chondrogenic, and osteogenic lineages. Blood 112: 295-307, 2008.

12. Kyurkchiev D, Bochev I, Ivanova-Todorova E, Mourdjeva M, Oreshkova T, Belemezova K and Kyurkchiev S: Secretion of immunoregulatory cytokines by mesenchymal stem cells. World J Stem Cells 6: 552-570, 2014.

13. Xiang MX, He AN, Wang JA and Gui C: Protective paracrine effect of mesenchymal stem cells on cardiomyocytes. J Zhejiang Univ Sci B 10: 619-624, 2009.

14. Rodrigues M, Turner O, Stolz D, Griffith LG and Wells A: Production of reactive oxygen species by multipotent stromal cells/mesenchymal stem cells upon exposure to fas ligand. Cell Transplant 21: 2171-2187, 2012.

15. Elahi MM, Kong YX and Matata BM: Oxidative stress as a mediator of cardiovascular disease. Oxid Med Cell Longev 2: 259-269, 2009.

16. Jin G, Qiu G, Wu D, Hu Y, Qiao P, Fan C and Gao F: Allogeneic bone marrow-derived mesenchymal stem cells attenuate hepatic ischemia-reperfusion injury by suppressing oxidative stress and inhibiting apoptosis in rats. Int J Mol Med 31: 1395-1401, 2013

17. Dominici M, Le Blanc K, Mueller I, Slaper-Cortenbach I, Marini F, Krause D, Deans R, Keating A, Prockop Dj and Horwitz E: Minimal criteria for defining multipotent mesenchymal stromal cells. The international society for cellular therapy position statement. Cytotherapy 8: 315-317, 2006. 
18. Brandl A, Meyer M, Bechmann V, Nerlich M and Angele P. Oxidative stress induces senescence in human mesenchymal stem cells. Exp Cell Res 317: 1541-1547, 2011.

19. Burova E, Borodkina A, Shatrova A and Nikolsky N: Sublethal oxidative stress induces the premature senescence of human mesenchymal stem cells derived from endometrium. Oxid Med Cell Longev 2013: 474931, 2013.

20. Supokawej A, Kheolamai P, Nartprayut K, U-Pratya Y, Manochantr S, Chayosumrit $M$ and Issaragrisil S: Cardiogenic and myogenic gene expression in mesenchymal stem cells after 5-azacytidine treatment. Turk J Haematol 30: 115-121, 2013.

21. Livak KJ and Schmittgen TD: Analysis of relative gene expression data using real-time quantitative PCR and the 2(-Delta Delta C(T)) method. Methods 25: 402-408, 2001.

22. Dunn KW, Kamocka MM and McDonald JH: A practical guide to evaluating colocalization in biological microscopy. Am J Physiol Cell Physiol 300: C723-C742, 2011

23. Sheikhzadeh F, Ward RK, Carraro A, Chen ZY, van Niekerk D, Miller D, Ehlen T, MacAulay CE, Follen M, Lane PM and Guillaud M: Quantification of confocal fluorescence microscopy for the detection of cervical intraepithelial neoplasia. Biomed Eng Online 14: 96, 2015.

24. Benameur L, Charif N, Li Y, Stoltz JF and de Isla N: Toward an understanding of mechanism of aging-induced oxidative stress in human mesenchymal stem cells. Biomed Mater Eng 25 (Suppl 1): S41-S46, 2015.

25. Gan P, Gao Z, Zhao X and Qi G: Surfactin inducing mitochondria-dependent ROS to activate MAPKs, NF- $\kappa \mathrm{B}$ and inflammasomes in macrophages for adjuvant activity. Sci Rep 6: 39303, 2016.

26. Zhao W, Zhao T, Chen Y, Ahokas RA and Sun Y: Oxidative stress mediates cardiac fibrosis by enhancing transforming growth factor-beta1 in hypertensive rats. Mol Cell Biochem 317: 43-50, 2008

27. Chen S, Chen X, Wu X, Wei S, Han W, Lin J, Kang M and Chen L: Hepatocyte growth factor-modified mesenchymal stem cells improve ischemia/reperfusion-induced acute lung injury in rats. Gene Ther 24: 3-11, 2017

28. Mureli S, Gans CP, Bare DJ, Geenen DL, Kumar NM and Banach K: Mesenchymal stem cells improve cardiac conduction by upregulation of connexin 43 through paracrine signaling. Am J Physiol Heart Circ Physiol 304: H600-H609, 2013.

29. Reppel L, Schiavi J, Charif N, Leger L, Yu H, Pinzano A, Henrionnet C, Stoltz JF, Bensoussan D and Huselstein C: Chondrogenic induction of mesenchymal stromal/stem cells from Wharton's jelly embedded in alginate hydrogel and without added growth factor: An alternative stem cell source for cartilage tissue engineering. Stem Cell Res Ther 6: 260, 2015.

30. Valle-Prieto A and Conget PA: Human mesenchymal stem cells efficiently manage oxidative stress. Stem Cells Dev 19 1885-1893, 2010

31. Balasubramanian S, Venugopal P, Sundarraj S, Zakaria Z, Majumdar AS and Ta M: Comparison of chemokine and receptor gene expression between Wharton's jelly and bone marrow-derived mesenchymal stromal cells. Cytotherapy 14 26-33, 2012.

32. Pu L, Meng M, Wu J, Zhang J, Hou Z, Gao H, Xu H, Liu B, Tang W, Jiang L and Li Y: Compared to the amniotic membrane, Wharton's jelly may be a more suitable source of mesenchymal stem cells for cardiovascular tissue engineering and clinical regeneration. Stem Cell Res Ther 8: 72, 2017.
33. Batsali AK, Pontikoglou C, Koutroulakis D, Pavlaki KI, Damianaki A, Mavroudi I, Alpantaki K, Kouvidi E, Kontakis G and Papadaki HA: Differential expression of cell cycle and WNT pathway-related genes accounts for differences in the growth and differentiation potential of Wharton's jelly and bone marrow-derived mesenchymal stem cells. Stem Cell Res Ther 8: 102,2017

34. Vinoth KJ, Manikandan J, Sethu S, Balakrishnan L, Heng A, Lu K, Poonepalli A, Hande MP and Cao T: Differential resistance of human embryonic stem cells and somatic cell types to hydrogen peroxide-induced genotoxicity may be dependent on innate basal intracellular ROS levels. Folia Histochem Cytobiol 53: 169-174, 2015

35. Ertaş G, Ural E, Ural D, Aksoy A, Kozdă̆ G, Gacar G and Karaöz E: Comparative analysis of apoptotic resistance of mesenchymal stem cells isolated from human bone marrow and adipose tissue. ScientificWorldJournal 2012: 105698, 2012.

36. Zhang G, Zou X, Huang Y, Wang F, Miao S, Liu G, Chen M and Zhu Y: Mesenchymal stromal cell-derived extracellular vesicles protect against acute kidney injury through anti-oxidation by Enhancing Nrf2/ARE activation in rats. kidney Blood Press Res 41: 119-128, 2016.

37. Zhang J, Chen GH, Wang YW, Zhao J, Duan HF, Liao LM, Zhang XZ, Chen YD and Chen H: Hydrogen peroxide preconditioning enhances the therapeutic efficacy of Wharton's Jelly mesenchymal stem cells after myocardial infarction. Chin Med J (Engl) 125: 3472-3478, 2012.

38. Zhang Y, Sivakumaran P, Newcomb AE, Hernandez D, Harris N, Khanabdali R, Liu GS, Kelly DJ, Pébay A, Hewitt AW, et al: Cardiac repair with a novel population of mesenchymal stem cells resident in the Human Heart. Stem Cells 33: 3100-3113, 2015.

39. Bai J, Hu Y, Wang YR, Liu LF, Chen J, Su SP and Wang Y: Comparison of human amniotic fluid-derived and umbilical cord Wharton's Jelly-derived mesenchymal stromal cells: Characterization and myocardial differentiation capacity. J Geriatr Cardiol 9: 166-171, 2012.

40. Wang FW, Wang Z, Zhang YM, Du ZX, Zhang XL, Liu Q, Guo YJ, Li XG and Hao AJ: Protective effect of melatonin on bone marrow mesenchymal stem cells against hydrogen peroxide-induced apoptosis in vitro. J Cell Biochem 114: 2346-2355, 2013

41. Choo KB, Tai L, Hymavathee KS, Wong CY, Nguyen PN, Huang CJ, Cheong SK and Kamarul T: Oxidative stress-induced premature senescence in Wharton's jelly-derived mesenchymal stem cells. Int J Med Sci 11: 1201-1207, 2014.

42. Wang Y, Yi XD and Li CD: Suppression of mTOR signaling pathway promotes bone marrow mesenchymal stem cells differentiation into osteoblast in degenerative scoliosis: In vivo and in vitro. Mol Biol Rep 44: 129-137, 2016.

43. López Y,Lutjemeier B, Seshareddy K, Trevino EM, Hageman KS, Musch TI, Borgarelli M and Weiss ML: Wharton's jelly or bone marrow mesenchymal stromal cells improve cardiac function following myocardial infarction for more than 32 weeks in a rat model: A preliminary report. Curr Stem Cell Res Ther 8: 46-59, 2013.

44. D'Autréaux B and Toledano MB: ROS as signalling molecules: Mechanisms that generate specificity in ROS homeostasis. Nat Rev Mol Cell Biol 8: 813-824, 2007.

45. Kobayashi CI and Suda T: Regulation of reactive oxygen species in stem cells and cancer stem cells. J Cell Physiol 227: 421-430, 2012. 